\title{
IMPLEMENTATION OF THE TERNARY BINDER IN SHOTCRETE DURING THE CONSTRUCTION OF THE METRO TUNNEL IN PRAGUE, CZECH REPUBLIC
}

\author{
ŠÁRKA PEŠKOVÁ, RADOSLAV SOVJÁK, VÍT ŠMILAUER, PAVEL RŮŽIČKA \& PETR KONVALINKA \\ Czech Technical University in Prague, Faculty of Civil Engineering, Czech Republic
}

\begin{abstract}
This paper summarizes recent achievements in shotcrete utilizing ternary binder. Ternary binder is composed mainly from fly ashes and, during hydration, produces large volumes of ettringite beneficial for early-strength gain in shotcrete. Savings in mineral resources, utilization of by-products and reduction in clinker consumption are seen as key benefits for the implemented solution. Design of ternary binder is discussed, including thermodynamical modelling and evolution of volume fractions in the binder. Ternary binder showed high stability with regards to input oxide variations, naturally occurring in heterogeneous fly ash production. Based on the results, a mock-up experiment was performed to verify the effectiveness of ternary binder in shotcrete with excellent results. Approximately 20 tons of the ternary binder is weekly consumed in the pilot project of metro D in Prague. Shotcrete serves as a temporary primary lining in the new Austrian tunnelling method. Substitute for cement in the form of ternary binder reached $50 \%$ for concrete strength class $\mathrm{C} 25 / 30$, following $\mathrm{J} 2$ curve strength gain.
\end{abstract}

Keywords: shotcrete, ternary binder, fly ash, ettringite, J2 curve, utilization.

\section{INTRODUCTION}

Coal combustion products (CCPs) are produced in considerable quantities all over the world and serve as resources for further products, such as concrete admixture [1]. In 2010, $780 \mathrm{Mt}$ were produced with 53\% average utilization rate [2]. Two fly ashes emerge from pulverized coal burning, namely:

- Classical fly ash

- Circulating fluidized bed combustion (CFBC) fly ash, emerging from co-combustion with lime-stone and capturing $\mathrm{SO}_{2}$ into anhydrous $\mathrm{CaSO}_{4}$.

Li et al. [3] studied hydration of CFBC fly ash itself and concluded that the main products are $\mathrm{C}-\mathrm{S}-\mathrm{H}$, ettringite and gypsum. Excessive volume expansions were often encountered, preventing direct use in Portland-based binders. Similar systems were used since 1970s in China, namely calcium sulfoaluminate (CSA) cements and CSA-belite cements [4]. Common hydrated phases included ettringite, strätlingite, monosulphate, amorphous $\mathrm{Al}(\mathrm{OH})_{3}$, and also $\mathrm{C}-\mathrm{S}-\mathrm{H}$ and portlandite with belite addition. As discussed further, the ternary binder yields similar hydrated phases as the CSA cement, were 40-year experience proved excellent performance [4]. Shotcrete presents an excellent opportunity for ternary binder utilization. Today, alkali-free accelerators are common approaches to induce early-age strength gain in shotcrete. They form large volumes of ettringite which can be obtained from ternary binder directly. This idea is further presented, from thermodynamical modelling and mock-up test to the pilot test.

\section{HYDRATION PHASES OF TERNARY BINDER}

The volumetric phase evolution was deduced from a combination of XRD measurements, deconvolution of DTG curves, porosimetry and SEM/EDX mappings [5]. Seven phases were 
distinguished; capillary and gel porosity, C-S-H globules, ettringite, amorphous glass, calcium hydroxide, and non-reactive crystalline phases; see Fig. 1.

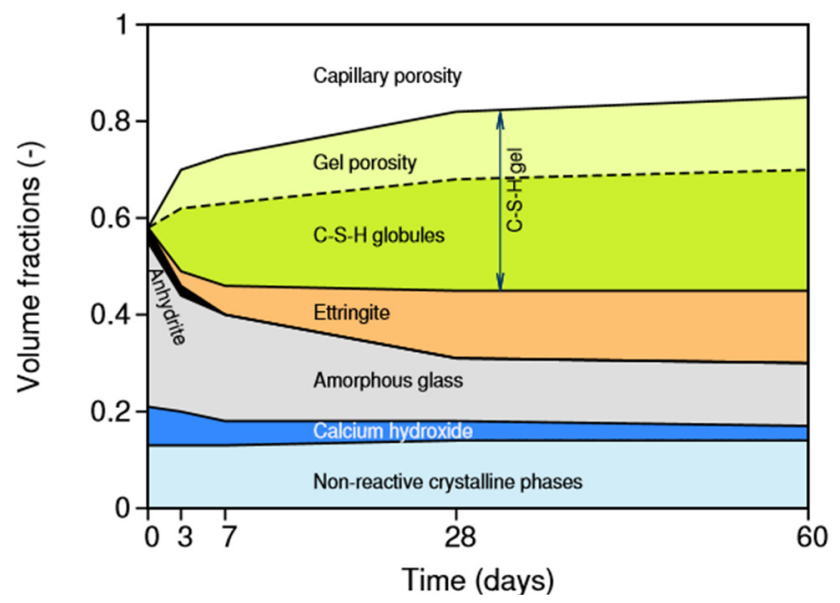

Figure 1: Volumetric model of phase evolution during hydration of ternary binder. (Source: Hlaváček et al. 2018 [5].)

The amount of non-reactive crystalline phases, calcium hydroxide, and remaining amorphous content stems from XRD analysis, while the amount of C-S-H gel and ettringite comes from DTG deconvolution. Volume fractions originate from the mass fractions of XRD, DTG data and densities of particular phases [5]. It could be noted that large volumes of ettringite are formed during hydration which could be utilized for early-age strength gain.

\section{THERMODYNAMIC MODELLING OF THE TERNARY BINDER}

Thermodynamic modelling became an essential part of cementitious binder design and optimization, able to provide hydrated phase assemblage in solid solution.

In order to shed light on phases evolution, thermodynamical modelling was employed for validation and sensitivity analysis. The initial mass $100 \mathrm{~g}$ of the ternary binder served as a reference system. First, it is necessary to estimate dissolved components in the solution, able to form hydrate assemblage. Fig. 1 gives indication about dissolution of ternary binder components and 60 days of hydration are considered. $62 \%$ of $\mathrm{Ca}(\mathrm{OH})_{2}$ and $45 \%$ of fly ashes reacted by that time. It is further estimated that conventional fly ash reacted by $15 \%$ and CFBC fly ash by $80 \%$. This affects mainly $\mathrm{SiO}_{2}, \mathrm{CaO}$ and $\mathrm{SO}_{3}$ availability in the pore solution.

In order to compare measured data with GEM-Selektor's prediction, it was necessary to resolve volume fractions. Several oxides were left out of the GEM-Selektor, particularly $\mathrm{Fe}_{2} \mathrm{O}_{3}, \mathrm{TiO}_{2}$, increasing unreacted part by approximately $2 \%$ by vol. Those oxides form small quantities of crystalline phases which are unimportant for microstructure evolution. Chemical shrinkage of real paste was estimated as $5 \%$ at 60 days of hydration.

Fig. 2 shows validation and sensitivity results with regards to initial oxide compositions. The column labelled "XRD+DTG" is re-plotted from Fig. 1 at the age of 60 days of sealed curing. The column "GEMS" shows the validation "as is", without further adjustments in GEMS. The model predicts $14 \%$ less volume in hydrates and also shows new gibbsite phase, unnoticed during previous XRD and DTG analysis. This might be the consequence of gibbsite's amorphous nature under this low Na concentration. 


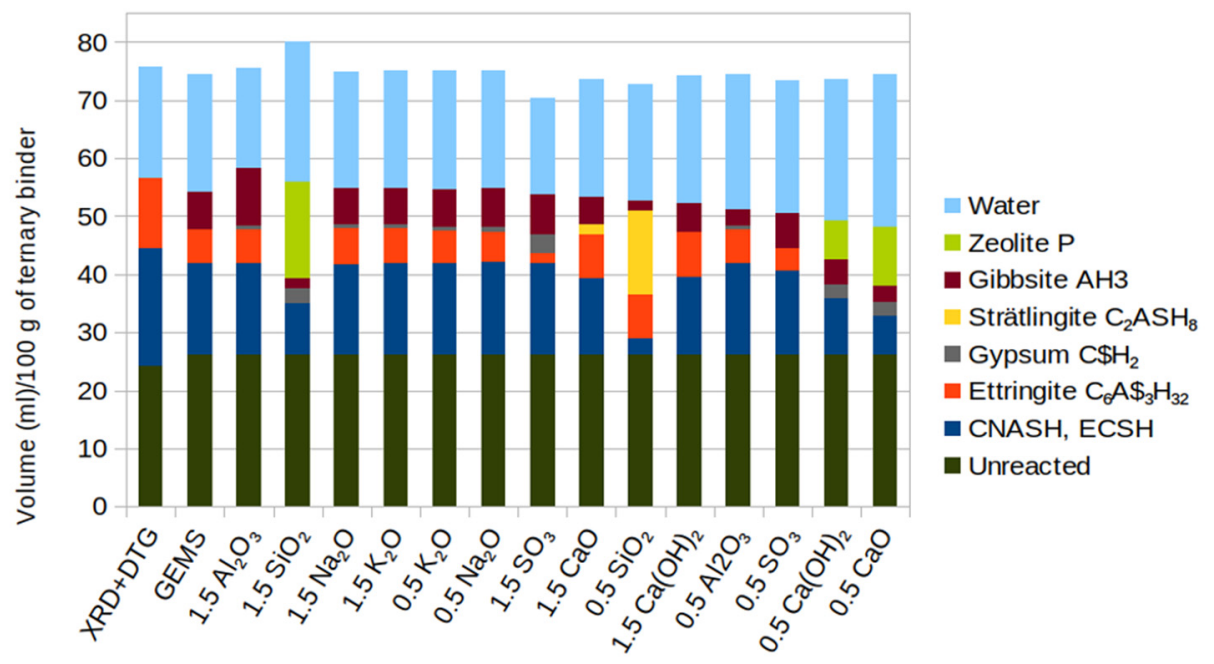

Figure 2: GEMS results and the sensitivity analysis of ternary binder.

Perturbations around the default oxide composition by $+50 \%$ and $-50 \%$ shows variations in hydrate assemblage. The ternary system is relatively stable within wide range of compositions; C-S-H and ettringite are usually formed as the two main hydrated phases, as noticed by other researchers [3]. Space-filling properties of hydrates are well preserved, reflected further in engineering properties such as strength gain or elasticity.

Different phases form at high deficiency or high excess of particular oxides. For example, zeolite $\mathrm{P}$ forms if deficiency in $\mathrm{CaO}$ exists, either provided by insufficient $\mathrm{CFBC}$ or $\mathrm{Ca}(\mathrm{OH})_{2}$ supply. Deficiency in $\mathrm{SiO}_{2}$ forms strätlingite at the expense of C-S-H while the excess in $\mathrm{SiO}_{2}$ generates Zeolite $\mathrm{P}$ on behalf of aluminates. Such high deviations may locally exist in the microstructure, preserving space-filling properties important for strength gain.

\section{SHOTCRETE WITH TERNARY BINDER IN MOCK-UP EXPERIMENT}

Positive results from microstructure analysis resulted in the mock-up experiment, which used $2 \mathrm{~m}^{3}$ of wet mix concrete according to Table 1 . Ternary binder substituted $44 \%$ of Portland cement. A truss-tunnel frame with the height of $5 \mathrm{~m}$ served for imitating a tunnel profile, see Fig. 3. The fallout was under $10 \%$, proving good adhesion and workability of the shotcrete. Strength evolution follows J2 curve as obtained by needle penetration test, 28 day compressive strength was determined from drilled cores, see Fig. 4.

Table 1: Mixture design.

\begin{tabular}{|l|c|}
\hline CEM I 42.5 R & $250 \mathrm{~kg}$ \\
\hline Ternary binder & $200 \mathrm{~kg}$ \\
\hline Water & $180 \mathrm{~kg}$ \\
\hline Aggregate $0-2 \mathrm{~mm}$ & $250 \mathrm{~kg}$ \\
\hline Aggregate $0-4 \mathrm{~mm}$ & $760 \mathrm{~kg}$ \\
\hline Aggregate $4-8 \mathrm{~mm}$ & $480 \mathrm{~kg}$ \\
\hline HRWR & $4 \mathrm{~kg}$ \\
\hline Alkali-free accelerator & $33.8(7.5 \%)$ \\
\hline
\end{tabular}




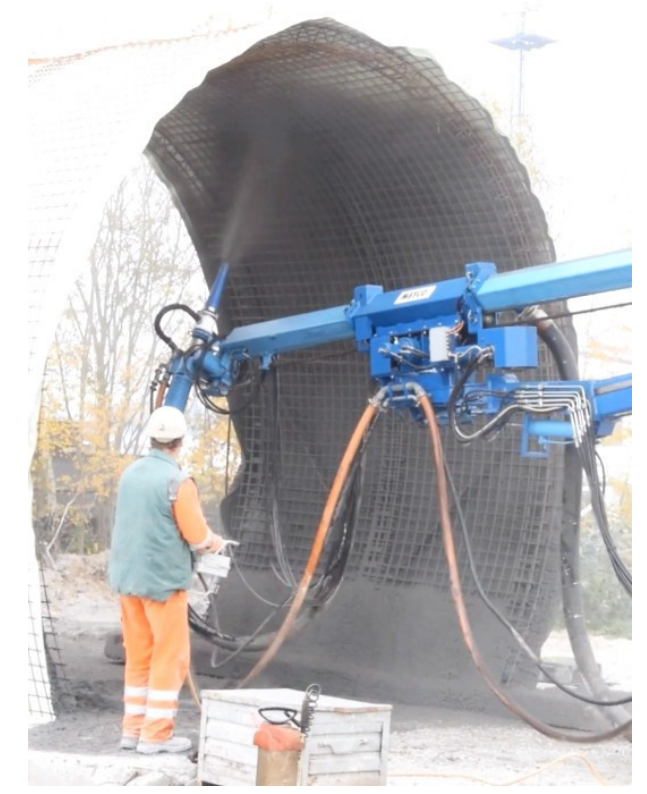

Figure 3: Mock-up experiment of shotcrete with ternary binder.

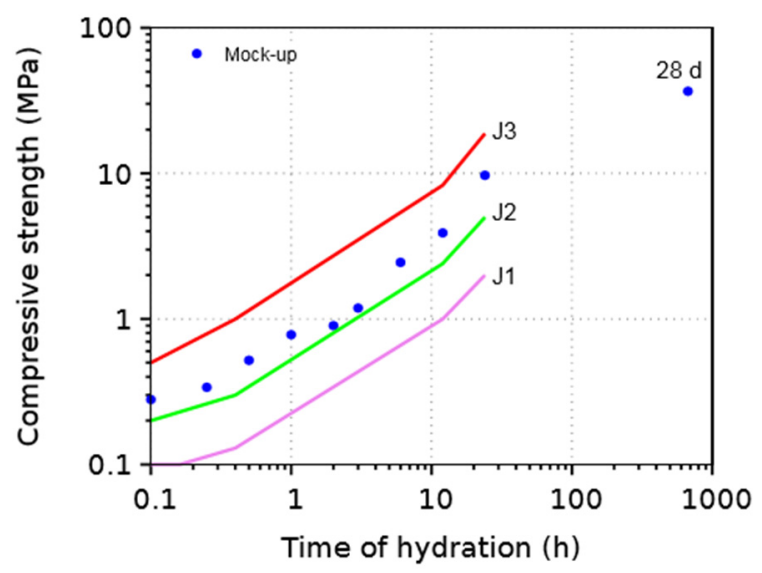

Figure 4: Strength evolution in the mock-up test.

Results from strength gain showed that ternary binder can easily substitute $44 \%$ of clinker, satisfying J2 curve required in several construction projects. Strength gain is very similar in standard shotcretes made from pure Portland cements, showing beneficial role of early ettringite formation from the ternary binder.

\section{PILOT TEST IN METRO LINING}

Promising results from mock-up test opened the way for larger pilot testing. Tunnel primary lining served for testing, serving as a temporary support until secondary lining is cast. The 
concrete mixture that was used to spray the walls of the subway lining was based on a series of laboratory tests in which a reasonable substitution of cement by a ternary binder at a level of about $50 \%$ was shown (Table 2 ).

Table 2: Mixture design.

\begin{tabular}{|l|c|}
\hline Aggregate 0/4 & $340 \mathrm{~kg}$ \\
\hline Aggregate 0/4 & $640 \mathrm{~kg}$ \\
\hline Aggregate 4-8 & $640 \mathrm{~kg}$ \\
\hline CEM I 42,5 & $230 \mathrm{~kg}$ \\
\hline Ternary binder & $200 \mathrm{~kg}$ \\
\hline Water & $195 \mathrm{~kg}$ \\
\hline HRWR & $4.3 \mathrm{~kg}$ \\
\hline Accelerator & $40.85 \mathrm{~kg}$ \\
\hline
\end{tabular}

The concrete mix was prepared in the concrete plant in volumes of about $8 \mathrm{~m}^{3}$ and was transported to the construction pit, where a test spraying was performed. The fresh concrete mixture was transported to the bottom of the construction pit by means of pipes when it was poured into the spraying machine. Several sample boxes for taking boreholes of hardened concrete were prepared next to the wall, where spraying would take place. The strength of the early age concrete mixture was determined on the basis of the penetration needle method and the nail driving method. The strength of the hardened concrete was later determined from boreholes in the conventional compression test.

The tested mixture shows a very good development of early strength over time, which is very useful for concrete in the lining of underground works. Even when using about $50 \%$ cement replacement with a ternary binder, the prescribed strength was observed, which can lead to significant savings in cement consumption in other similar underground works, where early age strain gain is an issue.

Figs 5 and 6 demonstrate situation on construction site which is the spraying of the mixture with the ternary binder on the shaft wall at its bottom and the spraying of the sample boxes. Fig. 7 displays strength evolution of the shotcrete, following mainly $\mathrm{J} 2$ curve.

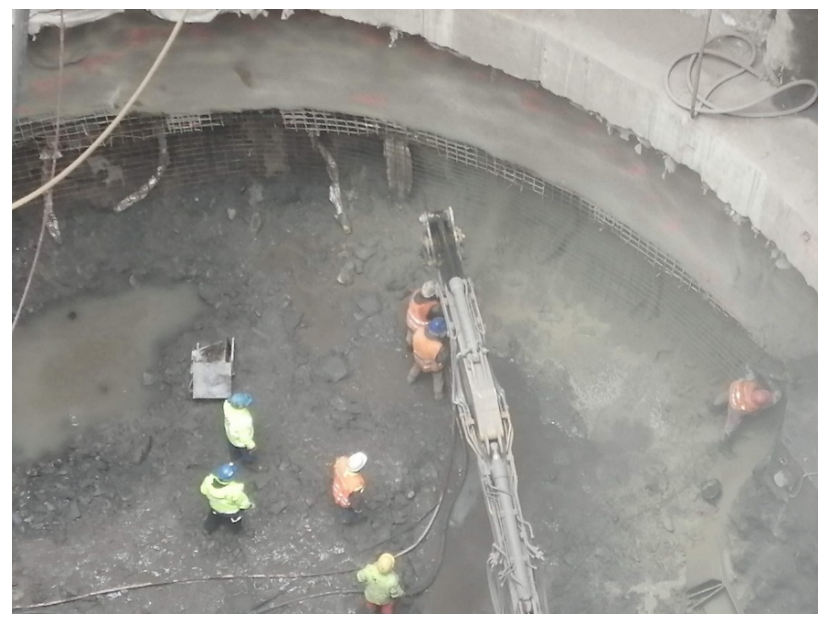

Figure 5: Detail of spraying of the mixture in the shaft. 


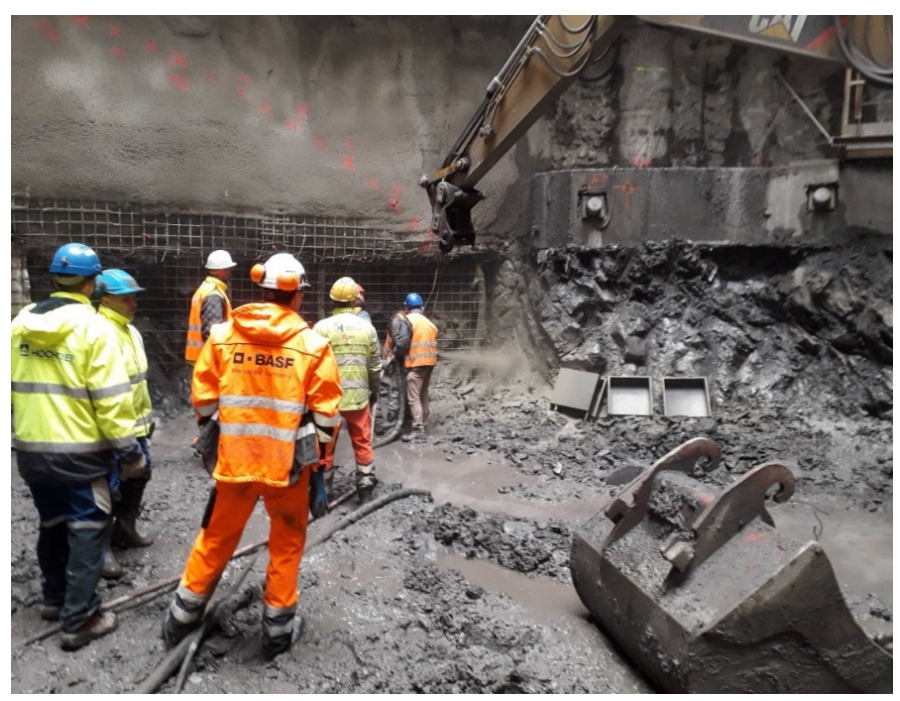

Figure 6: Spraying of the mixture to sample boxes.

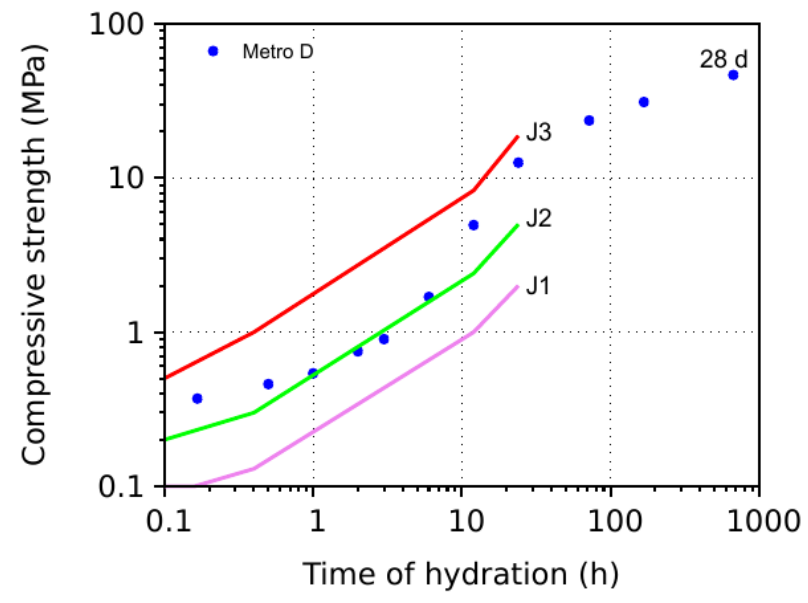

Figure 7: Strength development of the early age concrete of the tested mixture.

\section{CONCLUSIONS}

The paper summarizes main findings from the lab design, through mock-up experiment to large-scale pilot test. Based on the results of the tests the mixture with the ternary binder became used on the construction of Prague metro D. Utilization of coal combustion products in the ternary binder leads to cost saving, environmental benefits, $\mathrm{CO}_{2}$ reduction and lower clinker consumption. Shotcretes complied with the requirements of CSN EN 14487-1 [6] for the early strength class of curve $\mathrm{J} 2$, and shotcrete spraying showed successful application of the ternary binder. Further optimization of shotcrete is possible due to synergic experiments between lab and construction site. 


\section{ACKNOWLEDGEMENTS}

The authors gratefully acknowledge the financial support from the Technological Agency of the Czech Republic [project number TH02010206]. Support from university and company members is greatly appreciated, namely R. Šulc, F. Škvára, M. Šídlová, and R. Snop.

\section{REFERENCES}

[1] Robl, T., Oberlink, A. \& Jones, M., Coal Combustion Products (CCP's): Characteristics, Utilization and Beneficiation, 1st ed., Woodhead Publishing Limited, 2017.

[2] Heidrich, C., Feuerborn, H.-J. \& Weir, A., Coal combustion products: A global perspective. Proceedings of World of Coal Ash (WOCA) Conference, Lexington, KY, 2013.

[3] Li, X., Chen, Q., Huang, K., Ma, B. \& Wu, B., Cementitious properties and hydration mechanism of circulating fluidized bed combustion (CFBC) desulfurization ashes. Construction and Building Materials, 36, pp. 182-187, 2012.

[4] Harrison, T., Jones, M.R. \& Lawrence, D., Lea's Chemistry of Cement and Concrete (Fifth Edition), Butterworth-Heinemann, pp. 341-361, 2019.

[5] Hlaváček, P., Šulc, R., Šmilauer, V., Rössler, C. \& Snop, R., Ternary binder made of CFBC fly ash, conventional fly ash, and calcium hydroxide: Phase and strength evolution. Cement and Concrete Composites, 90, pp. 100-107, 2018.

[6] ČSN, EN 14487-1: Sprayed concrete - Part 1: Definitions, specifications and conformity. 